\title{
Klebsiella pneumoniae hipervirulenta
}

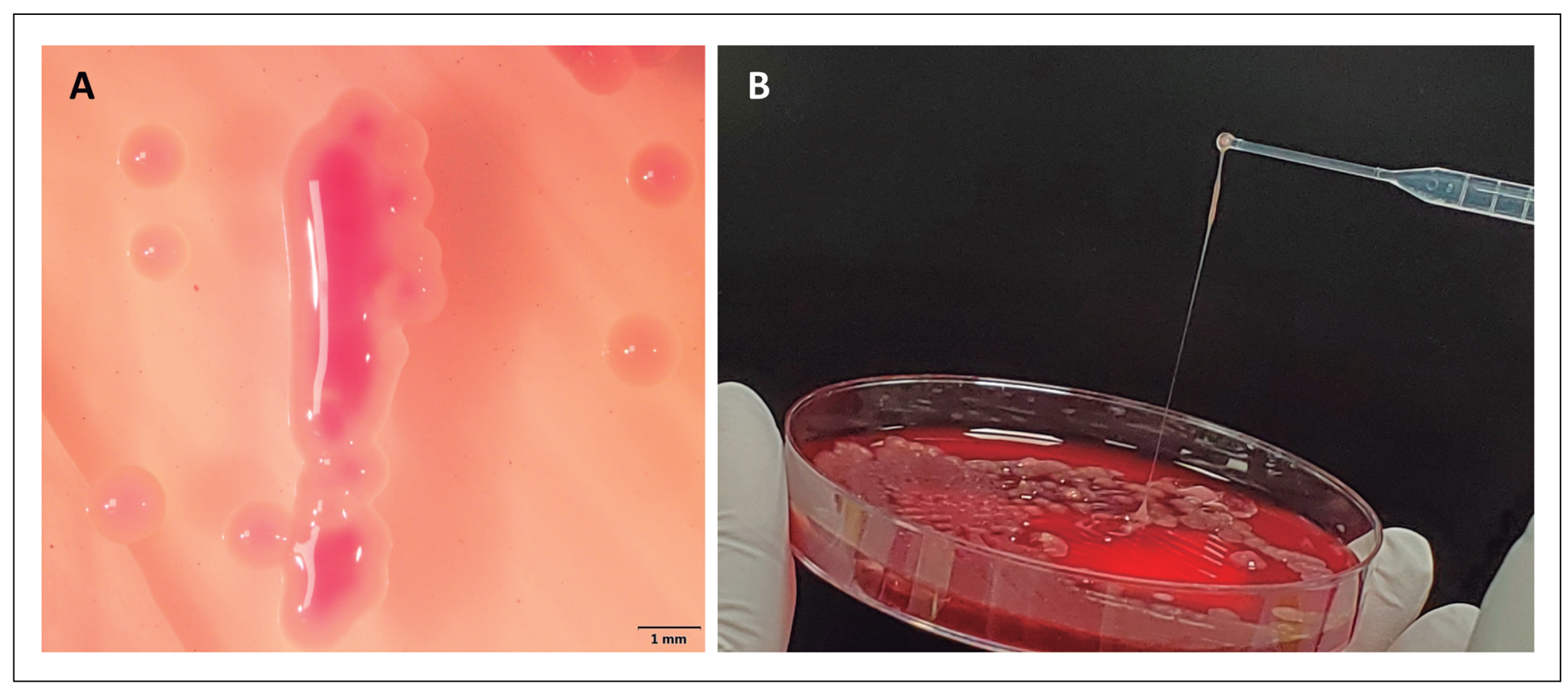

Figura 1. Cepa de Klebsiella pneumoniae con fenotipo hipermucoviscoso aislada de una muestra de un absceso hepático en paciente chileno sin antecedente de viaje internacional. A. Colonia lactosa positiva en agar MacConkey de aspecto hipermucoso. B. "String test" positivo de la colonia en agar sangre. 


\section{Klebsiella pneumoniae hipervirulenta}

Klebsiella pneumoniae hipervirulenta (hvKp) es un patotipo emergente que presenta mayor virulencia que K. pneumoniae clásica (cKp). Tiene la capacidad de causar infecciones graves y potencialmente fatales en individuos previamente sanos. Se describió por primera vez en 1986 en el Sudeste asiático, donde actualmente se concentra la mayoría de los casos en el mundo. No obstante, también se ha descrito en Norteamérica y Europa. En Sudamérica, tanto Brasil como Argentina ya se han reportado infecciones humanas. La manifestación clínica más característica es un absceso hepático sin antecedentes de enfermedad del tracto biliar. Otras presentaciones son la neumonía y las infecciones diseminadas que afectan múltiples órganos o producen infecciones metastásicas como fascitis necrosante, endoftalmitis y meningitis. Estos cuadros se asocian a tasas de mortalidad que varían entre 3 y $42 \%$, aunque pueden alcanzar hasta $55 \%$ en el caso de neumonía bacteriémica. Además, los sobrevivientes de infecciones críticas frecuentemente presentan secuelas graves, tales como pérdida de la visión, daño neurológico o pérdida de una extremidad.

Generalmente, hvKp se asocia a la hiperproducción de una cápsula mucosa que en el 70\% de los casos pertenece a los serotipos K1 y K2. La característica fenotípica asociada a esta gran producción de cápsula es la "hipermucoviscosidad", que se traduce en colonias de aspecto mucilaginoso y con alta filancia (Figura 1, Panel A). Esta última se evidencia mediante el "string test", considerándose positivo cuando al tocar la colonia con un asa de cultivo se logra generar una "cuerda" viscosa que se extiende desde la superficie del agar por 5 mm o más (Figura 1, Panel B). Esta prueba no es confirmatoria de hvKp, ya que el mismo fenotipo puede manifestarse ocasionalmente en cKp. Sin embargo, una prueba negativa puede presentar un valor predictivo negativo de $97 \%$, según un estudio en aislados de bacteriemia comunitaria en Singapur, permitiendo descartar el fenotipo hipervirulento. Si bien aún no existe una prueba confirmatoria establecida para las cepas hvKp, un estudio reciente sugiere que los marcadores moleculares más confiables para definirlas son los genes iroB, iucA, peg-344, rmpA у rmpA2, presentes en plásmidos de virulencia o en elementos integrativos y conjugativos (iro, peg-344, rmpA). Las cepas de hvKp suelen ser sensibles a la mayoría de los antimicrobianos y a la fecha no han adquirido determinantes de resistencia antimicrobiana con la velocidad que lo ha hecho cKp. Sin embargo, en Asia ya se ha descrito un aumento de la prevalencia de cepas nosocomiales hvKp multi-resistentes, incluyendo cepas productoras de BLEE y de carbapenemasas (KPC), principalmente en pacientes con infecciones asociadas a la atención de salud. Dado que la diseminación de una cepa hipervirulenta en pacientes hospitalizados podría tener graves consecuencias, se recomienda implementar precauciones de contacto frente a su sospecha.

En Chile no existen datos epidemiológicos sobre hvKp y su diagnóstico es solo presuntivo, basado en la sospecha clínica y la característica hipermucosa de las colonias con un "string test" positivo. Dado el carácter emergente de este patógeno, parece importante establecer en Chile una vigilancia de laboratorio, incluyendo análisis moleculares confirmatorios.

\section{Referencias bibliográficas}

1.- Harada S, Aoki K, Yamamoto S, Ishii Y, Sekiya N, Kurai H, et al. Clinical and molecular characteristics of Klebsiella pneumoniae isolates causing bloodstream infections in Japan: occurrence of hypervirulent infections in health care. J Clin Microbiol 2019; 57: e01206-19. doi: 10.1128/JCM.0120619.

2.- $\quad$ Liu C, Du P, Xiao N, Ji F, Russo T, Guo J. Hypervirulent Klebsiella pneumoniae is emerging as an increasingly prevalent K. pneumoniae pathotype responsible for nosocomial and healthcare-associated infections in Beijing, China. Virulence 2020; 11: 1215-24. doi: 10.1080/21505594.2020.1809322

3.- Russo T, Marr CM. Hypervirulent Klebsiella pneumoniae. Clin Microbiol Rev 2019; 32: e00001-19. doi: 10.1128/CMR.00001-19.

4.- Shon A, Bajwa R, Russo T. Hypervirulent (hypermucoviscous) Klebsiella pneumoniae a new and dangerous breed. Virulence 2013; 4: 107-118. doi: 10.4161/viru.22718.

5.- Tan TY, Cheng Y, Ong M, Ng LSY. Performance characteristics and clinical predictive value of string test for detection of hepato-virulent Klebsiella pneumoniae isolated from blood cultures. Diagn Microbiol Infect Dis 2014; 78: 127-128. doi: 10.1016/j.diagmicrobio.2013.10.014.

Silvina López ${ }^{1}$, Lorena Porte ${ }^{1}$ y Thomas Weitzel

${ }^{1}$ Laboratorio Clínico, Clínica Alemana, Santiago de Chile.

Facultad de Medicina Clínica Alemana, Universidad del Desarrollo, Santiago de Chile. 